

\section{DISCLAIMER}

This report was prepared as an account of work sponsored by an agency of the United States Government. Neither the United States Government nor any agency Thereof, nor any of their employees, makes any warranty, express or implied, or assumes any legal liability or responsibility for the accuracy, completeness, or usefulness of any information, apparatus, product, or process disclosed, or represents that its use would not infringe privately owned rights. Reference herein to any specific commercial product, process, or service by trade name, trademark, manufacturer, or otherwise does not necessarily constitute or imply its endorsement, recommendation, or favoring by the United States Government or any agency thereof. The views and opinions of authors expressed herein do not necessarily state or reflect those of the United States Government or any agency thereof. 


\section{DISCLAIMER}

Portions of this document may be illegible in electronic image products. Images are produced from the best available original document. 
Reference to a company or product name does not imply approval or recommendation of the product by Union Carbide Corporation or the U.S. Energy Research and Development Administration to the exclusion of others that may meet specifications.

Printed in the United States of America. Available from National Technical Information Service

U.S. Department of Commerce

5285 Port Royal Road, Springfield, Virginia 22161

Price: Printed Copy $\$ 3.50$; Microfiche $\$ 3.00$

This report was prepared as an account of work sponsored by the United States Government. Neither the United States nor the Energy Research and Development Administration, nor any of their employees, nor any of their contractors, subcontractors, or their employees, makes any warranty, express or implied, or assumes any legal liability or responsibility for the accuracy, completeness or usefulness of any information, apparatus, product or process disclosed, or represents that its use would not infringe privately owned rights. 


\title{
AN AUTOMATED ATOMIC ABSORPTION SPECTROPHOTOMETER, UTILIZING A PROGRAMMABLE DESK CALCULATOR
}

\author{
T. L. Futrell \\ R. W. Morrow \\ Y-12 Plant Laboratory \\ Product Certification Division
}

Adapted from a paper that was presented at the Pitisburgh Conference on Analytical Chemistry and Applied Spectroscopy, Cleveland, Ohio, March 2-7, 1975.

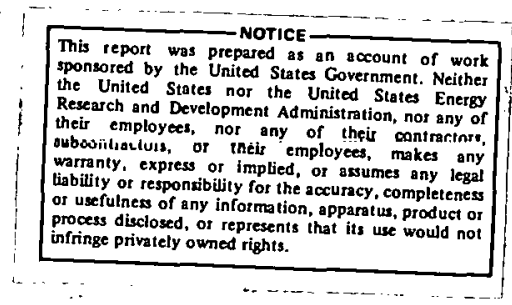

Oak Ridge Y-12 Plant

P. O. Box Y, Oak Ridge, Tennessee 37830

Prepared for the US Energy Research and Development Administration Under US Government Contract W-710E-eng-26 


\begin{abstract}
A commercial, double-beam atomic absorption spectrophotometer has been interfaced with a sample changer and a Hewlett-Packard $9810 \mathrm{~A}$ calculator to yield a completely automated analysis system. The interface electronics can be easily constructed and should be adaptable to any double-beam atomic absorption instrument. The calculator is easily programmed and can be used for general laboratory purposes when not operating the instrument. The automated system has been shown to perform very satisfactorily when operated unattended to analyze a large number of samples. Performance statistics agree well with a manually operated instrument.
\end{abstract}




\section{CONTENTS}

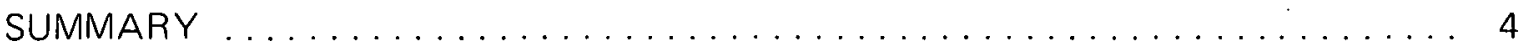

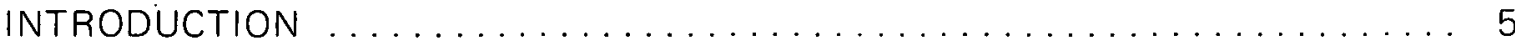

AN AUTOMATED ATOMIC ABSORPTION SPECTROPHOTOMETER . . . . . . 6

Experimental Work ... . . . . . . . . . . . . . . . . . . . . . . . . 6

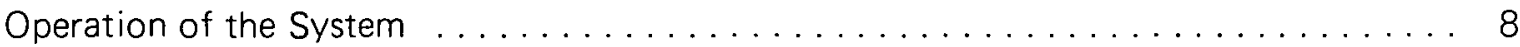

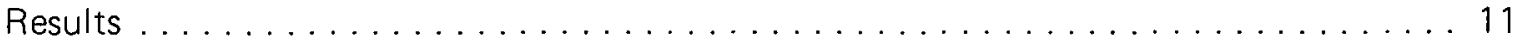

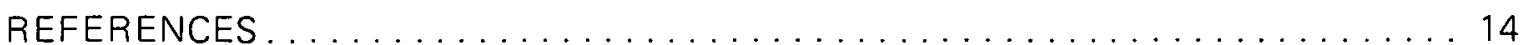




\section{SUMMARY}

A programmable desk calculator has been interfaced with a double-beam atomic absorption spectrophotometer and a mechanical sample changer to provide automated analysis by either flame emission or atomic absorption. The calculator controls the spectrophotometer and sample changer during analysis, makes a second-order, least-squares fit to the computed absorbance or emission of standards, and then calculates the concentration of each sample. The analog signal from the photomultiplier of the spectrophotometer is synchronously demodulated into dark current, reference, and measure components (or only the measure component in the emission mode). These signals are then respectively integrated. The calculator reads the output of each integrator with an analog-digital converter and then computes the absorbance and concentration of the sample.

Application of the spectrophotometer can be made to analyze industrial process water, environmental water, and alloys. Analytical results and precision compare favorably with results obtained by manual operation of the instrument. 


\section{INTRODUCTION}

The atomic absorption/calculator system described in this document arose from a need at the Oak Ridge Y-12 Plant(a) to improve the performance of a Jarrell-Ash Model 810 atomic absorption spectrophotometer through automation. Previous work on the automation of commercial atomic absorption instruments has used digital computers for instrument control and data processing. $(1,2)$ Although both a minicomputer and a Hewlett-Packard 9810A calculator were available, the calculator was selected for use. Ease in programming the calculator and in making the necessary program changes compared to digital computer programming was the principal reason for making the choice. Also, when not controlling the instrument, the calculator is available for ordinary laboratory computations.

(a) Operated by the Union Carbide Corporation's Nuclear Division for the US Energy Research and Devclopment Adminislration. 


\section{AN AUTOMATED ATOMIC ABSORPTION SPECTROPHOTOMETER}

\section{EXPERIMENTAL WORK}

In developing a design approach; the extent to which the Jarrell-Ash electronics would be utilized by the automated instrument was first established. Use of both channels of the dual-channel, double-beam spectrophotometer was never considered, since only Channel $A$ permits a manual control of the photomultiplier high voltage. While the Model 810 spectrophotometer does have an internal auto-zero feature, it was felt that a more stable system could be devised if the analog signal were allowed to "float" and to perform all signal conditinning within the programmable calculator. In addition, the calculator was utilized for taking logarithms, thereby eliminating the inherent inaccuracy of a logarithmic electronic amplifier. The statistıcal-analysls capaluililies of the calculator would permit a more accurate approach to correcting the nonlinear absorbance function sometimes encountered. As a result of these design criteria, the only Jarrell-Ash electronics utilized are the Channel A photomultiplier and its high-voltage power supply.

Automation of the atomic absorption spectrophotometer to collecl and process data, to print the analytical result, and to change samples, all with no operator attention, required construction of an interface unit. With this interface, the calculator effectively controls the automatic sample changer and the atomic absorption instrument. A block diagram showing the interface electronics, the calculator, and the sample changer is presented in Figure 1.

Effective automation of the spectrophotometer required the use of a sample charlyer that could accommodate up to 150 samples plus the standards. The Gilson Mudical Electronics Model SC.15 r.hanger was selected. Individual tmers are provided fur both the samplo and rinse sycless. The unit was modified to permit on-line control by the prougramilable calculator.

The heart of the control and data processing system is a Hewlett-Packard Model 9810A programmable salculator. This calculator is equipped with 500 program steps, 51 data storage registers, a thermal printer, a statıstics read unly memory (ROM), and a paper-tape reader. The programming larnyuage is Reverse Polish Notation.

A block diagram of the electronics system is included in Figure 1. On the extrome left is the photomultiplier tube and the associaled siynal waveform. Bumbth the photnmultiplier waveform are shown the synchronization signals representing the photomultiplier dark current, the reference bearr, and the measurc beam. These synchronization signals are developed within the spectrophotometer and are related to modulation of the hollow cathode lamp and to the beam chopper.

The output of the photomultiplier is fed to a preamplifier with high-input impedance and an extremely low input bias current. The preamplifier output is then applied to three matched integrators. The integrators make use of chopper-stabliized operational amplifiers 


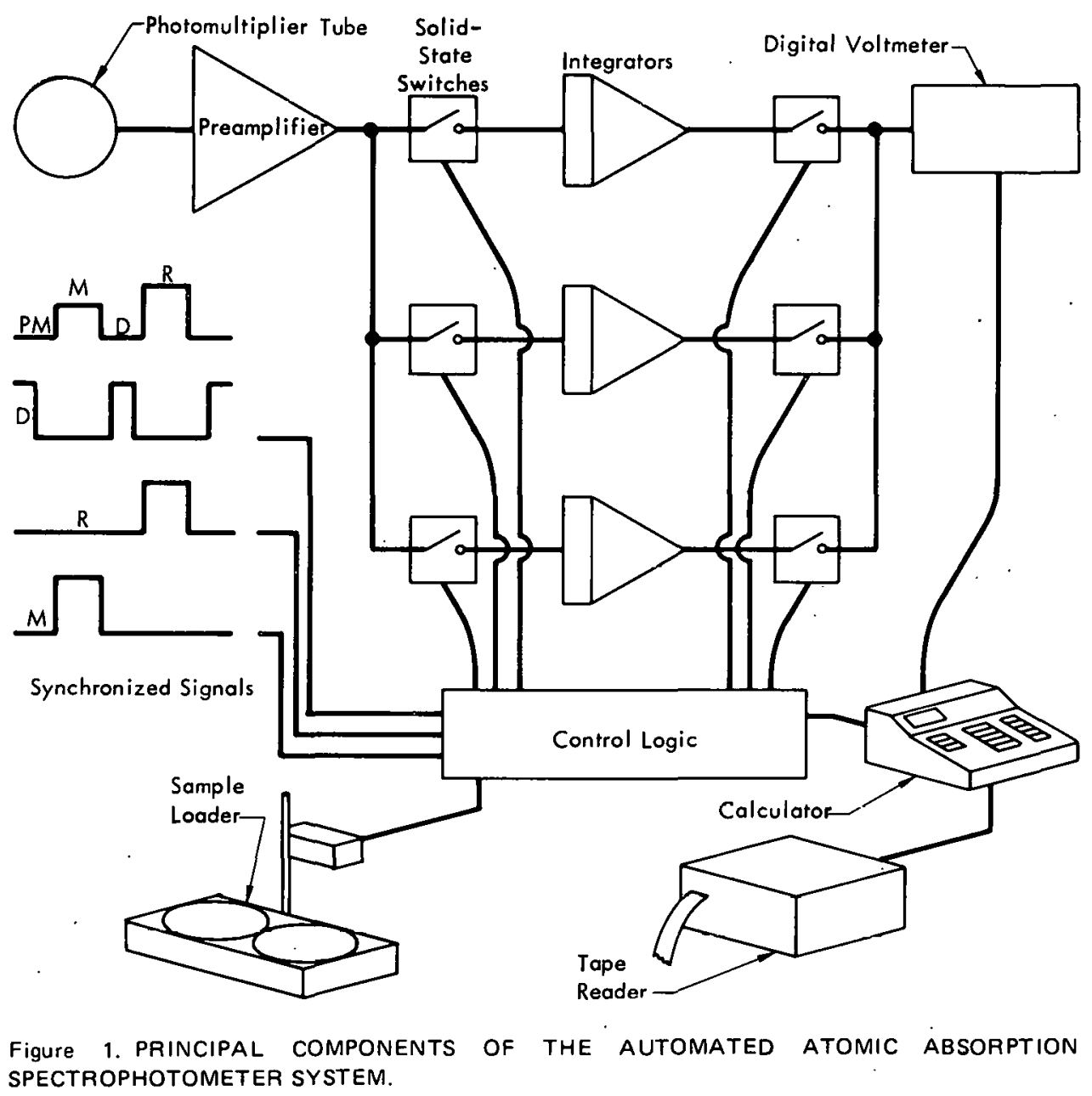

and low-leakage polystyrene capacitors. Solid-state switches are used to synchronously demodulate the input to the integrators such that each of the three signals of interest are summed in separate integrators. The output of the integrators is selectively applied to a digital voltmeter, which has binary coded decimal ( $B C D$ ) outputs for input to the calculator.

As is shown in the diagram, the calculator has a standard BCD interface to the voltmeter, a standard interface to the paper-tape reader, and a universal transistor transistor logic (TTL) interface to the control logic which was designed for this application. The calculator can independently address either of these interface.lines. The Gilson sample changer is uperated by the calculator through the currtrul lugic irlu face.

Data are taken by the calculator in the following manner: Under program control, and "integrate" command is given. The three synchronization signals are gated by the control logic and applied to the input solid-state switches. After 400 reference synchronization pulses have accumulated in a digital counter, a flag is returned to the calculator, signaling the end of integration. The calculator then sequentially gates the integrator outputs to the voltmeter dnd lhte vultmeter readings are stored in momory registers. The 
calculator may then reset the integrators, change to the next sample, and read sample identification information from the paper tape.

Data input to the calculator in this manner may be handled in various ways. For a typical flame absorption program, the three equations shown in Figure 2 apply. Equation 1 demonstrates how an effective auto zero is accomplished within the calculator. During the rinse cycle before each sample, an integration is made while aspirating water. The dark current is subtracted from both the measure and reference beam signals, and a ratio is taken which represents the relative intensity of the two beams. The resulting constant, $K$, is a gain factor which must be applied to the measure beam signal when analyzing the following sample. Any drift in the instrument parameters that affect only the measure beam, and consequently the instrument

1. $K=\frac{R-D}{M-D}$, when Aspirating Water,

Where: $R$ Represents the Reference Beam Intensity, $M$ the Measure Beam Intensity, and

D the Dark Current.

2. $A B S=\log _{10} \frac{R-D}{K(M-D)}$

3. Concentration $=A(A B S)^{2}+B(A B S)+C$.

Figure 2. EQUATIONS USED FOR ANALYSIS CALCULATIONS. zero, is effectively compensated for by determining this factor before each sample analysis, thereby resulting in an automatic adjustment of the instrument zero.

When aspirating the sample, Equation 2 is applied to determine absorbance (ABS) of the sumple. As shown in the equation, the previously determined gain factor $(K)$ is applied to the measure beam signal. The equation represents the logarithm of the ratio of incident energy to transmitted eneryy.

Preceding each series of samples, a group of standards are analyzed. The calculator performs a second-order, least-squares fit of concentration to absorbance, thereby producing the coefficients ( $\mathrm{A}, \mathrm{B}$, and $\mathrm{C}$ ) of Equation 3. This equation is then used to calculate the concentration of all subsequent samples.

\section{OPERATION OF THE SYSTEM}

Figure 3 is a photograph of the complete system. The sample changer, calculator, and paper-tape reader are shown positioned in front of the Jarrell-Ash instrument. Tho interface module is located on top of the monochromator section of the instrument.

To operate the system, the Jarrell-Ash atomic absorption spectrophotometer is optimized, using the manufacturer's suggested operating conditions for wavelength, lamp current, and spectral slit width. The interface module is then connected to the instrument. and the photomultiplier voltage adjusted to bring the beam intensity meter on scale. With the interface selector switch in the "dark current" position, the meter is brought to a zero reading using the interface zero control. The meter is then made to 


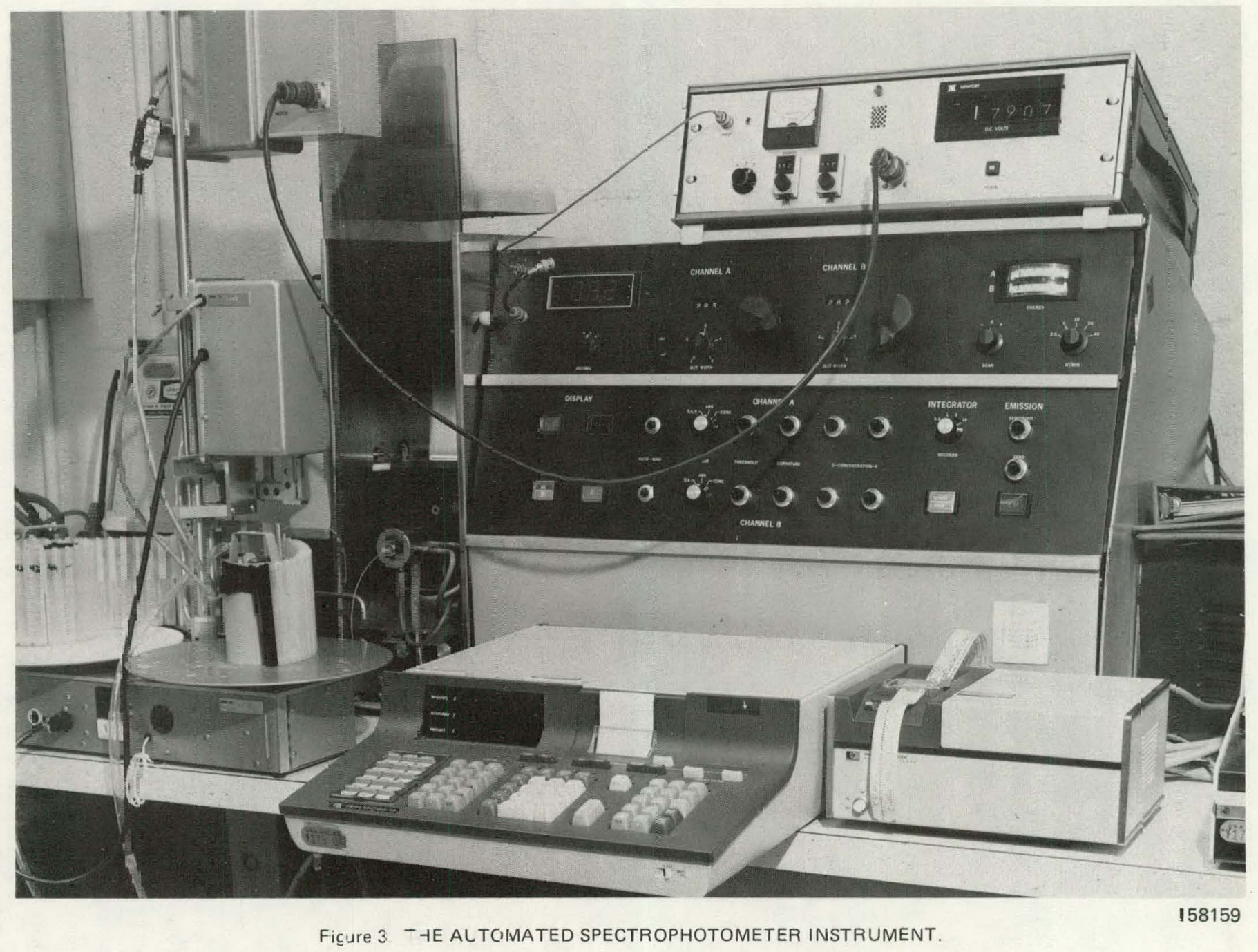


read in the middle of the red optimum zone when the selector switch is in the "measure" or "reference" position by varying the calibrate control on the interface or by varying the photomultiplier voltage.

Standard solutions are loaded in consecutive order by using the first of the vials in the sample spool. The prepared samples are then loaded in the remaining vials with the check or control standard inserted after every fourth sample. From 100 to 150 samples can be accommodated on a single spool.

The sample changer is positioned in front of the burner, the sampling pipet is connected to the burner atomizer, and a demineralized water line is connected to the inse vial. The sample spool is mounted on the changer and the first sample rotated into position. The sampling pipet is lowered into the rinse vial and the sample and rinse timers set at five seconds each. The sample changer is now ready for an operating command from the calculator.

The master absorption (or emission) program card is read into the calculator, followed by a standard program card for the partıcular standard series to be iuı. The paper-tapc reader is loaded with a tape containing the sample identification numbers.

Operation of the automatic atomic absorption spectrophotometer is initiated by the operator by pushing the "continue" button on the calculator. The pipet remains in the rinse vial tor the initial five seconds on the limer dind llien for an additional scven seconds while both beam intensities and dark current are integrated. After the calculator has received the net "zero" absorption data from the interface, it signals the pipet to move to the vial contaıning the first standard. Here it remains vvliile the signals are again integrated. The voltage readings are transmitted to the calculator and the calculator then signals the pipet to return to the rinse vial and the sample changer to advance the next vial into position. This process is then repeated until all standards have been aspirated. Then, the operator is signaled that calibration is complete. Finally, the calculator prints out the calibration data. If a salisfactury calibration is obtained, the opcrator presses "continue" and the sample analysis commences.

A typical calculator printout from a magnesium anlalysis, bulh calibration and sample concentration results, is presented in Figure 4. The first series of numbers shown are the magnesium concentrations (as the carbonate) in the standards. The check standard concentration is seen to be $60 \mu \mathrm{g} / \mathrm{ml}$ of the carbonate and a deviation of $\pm 15 \%$, or $9 \mu \mathrm{g} / \mathrm{ml}$ of the carbonate is allowed. The A, B, and C constants of the second-order equation are printed next. This calibration curve is seen to have a zero intercept from the value of the $\mathrm{C}$ coefficient and has a degree of curvature as indicated by the $A$ value. The computed correlation coefficient is probably the number of most significance to the analyst. It is a measure of how well the computed values of the standards fit about the calibration curve generated from the computed constants of the equation. 


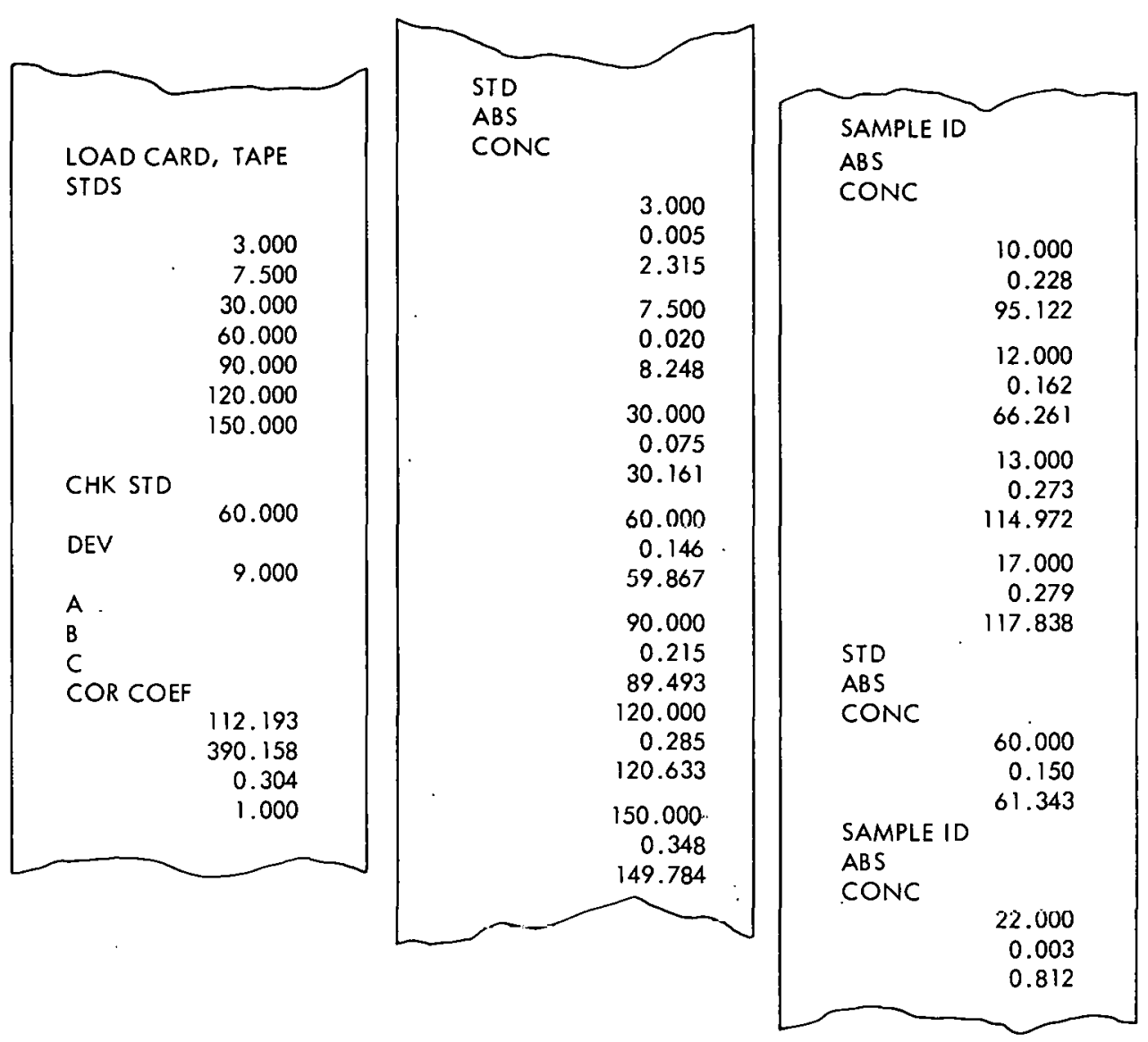

Figure 4. A TYPICAL CALCULATOR PRINTOUT. (An Analysis for Magnesium)

The known value of the. standard, its computed absorbance, and the computed concentration are printed next. At this point, the system stops automatically after calibration. The laboratory analyst can examine the computed standard values along with the correlation coefficient and decide if an adequate calibration has been achieved.

When the system is told to continue, it will print the sample identification number as read from the tape, the computed absorbance of the sample, and, in this case, the concentration of magnesium expressed as the carbonate. After four samples have been run, a check standard is analyzed. Known values of the check standard, the computed absorbance, and the determined concentration are printed. If these values are within the preset limits, the system will continue and analyze the next sample. When the preset deviation is exceeded, the system stops, the alarm sounds, and the operator must decide either to continue or to rccalibrate.

\section{RESULTS}

Figure 5 provides a plot of magnesium cuncentration (as the carbonate) as a function of absorbance computed by the calculator. The surve is seen to be alightly riunlinedr. but tits the known standard values very well. Calibration curves that do not follow 
Beer's law can be used with this system up to absorption values of 95 to $98 \%$. This provision is a considerable advantage over a manually operated instrument when burner-rotation and curve-correction electronics must be used.

Results of analyzing a number of water samples for magnesium carbonate, using the automated atomic absorption instrument and using an inctrument operated manually, are indicated by the graph of Figure 6. The line represents à leasl-syuares fit through the data points. The unity slope indicates that there is an excellent agreement between the values obtained by the calculator-data system and the values obtained from the digital-concentration readout of the commercial atomic absorption instrument.

A statistical comparison of data taken with the alıtomated Jarrell-Ash instrument and with the same instrument operated manually was completed. The results of this sludy are reported in Table 1 . The elements and the concentration used dre sliown in the loft column. These standards were anlalyzed repetitively up to 20 times in a given run, using the Jarrell-Ash instrument in the automated and manual modes. The mean $(\bar{X})$ and the percent relative standard deviation (RSO) of the medrl are given for the results nhtained from manual and automated operation. Calcium was deter-

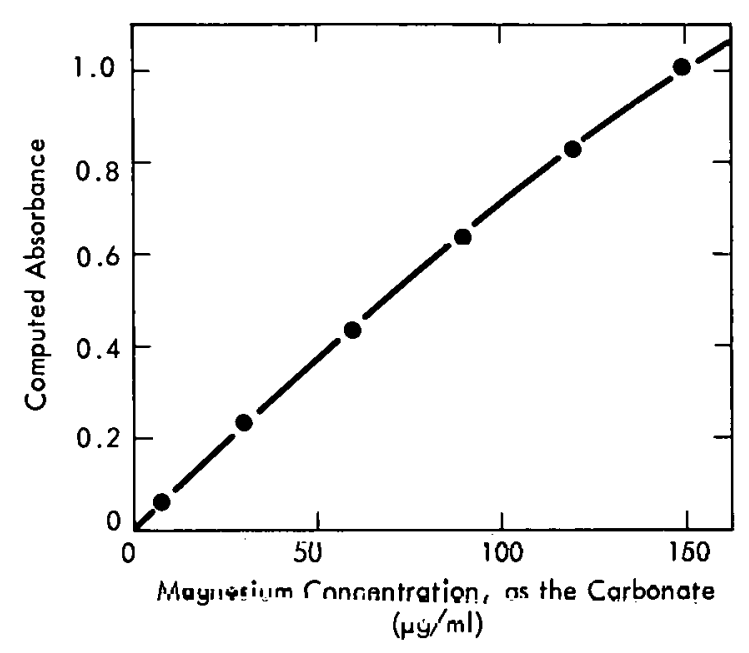

FiguIE 5. CALIBRATION CURVE FOR MAGNESIUM.

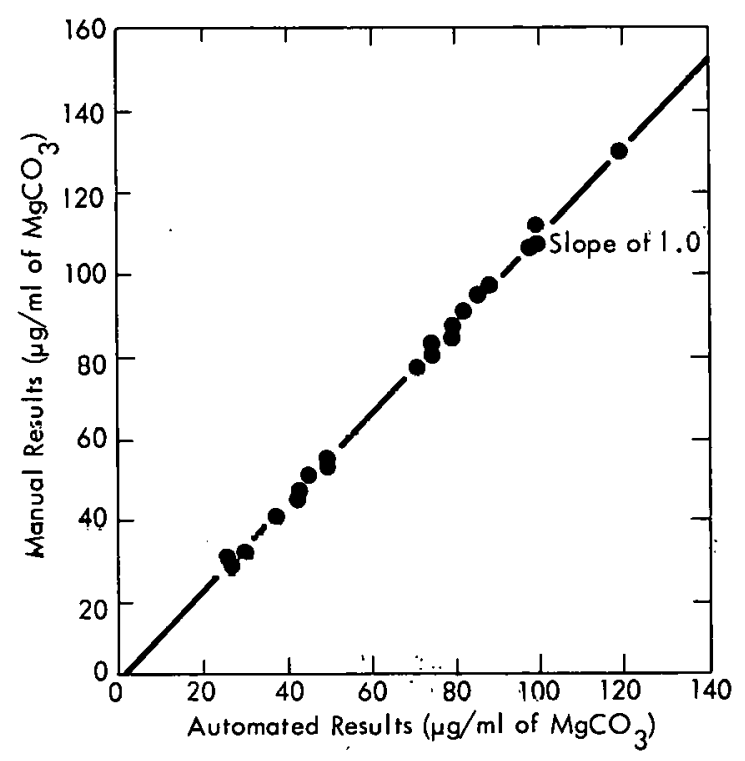

Figure 6. COMPARISON OF ANA'LYTICAL RESULTS.

Table 1

STATISTICAL COMPARISON OF ANALYTICAL RESULTS (Within-Run Precision and Accuracy)

\begin{tabular}{|c|c|c|c|c|}
\hline \multirow[b]{3}{*}{ Element } & \multicolumn{4}{|c|}{ Operation Type } \\
\hline & \multicolumn{2}{|c|}{ Automated } & \multicolumn{2}{|c|}{ Manual } \\
\hline & $\bar{x}$ & Pércent RSD & $x$ & Percent RSD \\
\hline $\mathrm{Ca}(44.4 \mu \mathrm{g} / \mathrm{ml})$ & 45.2 & 2.7 & 43.7 & 3.4 \\
\hline $\mathrm{Cu}(2.0 \mu \mathrm{g} / \mathrm{ml})$ & 1.99 & 1.0 & 1.89 & 2.6 \\
\hline$F_{\theta}(2.0 \mu \mathrm{g} / \mathrm{ml})$ & 1.95 & 1.9 & 1.97 & 1.0 \\
\hline $\mathrm{Mg}(17.1 \mu \mathrm{g} / \mathrm{ml})$ & 17.9 & 2.3 & 17.1 & 1.8 \\
\hline
\end{tabular}


mined by flame emission while copper, iron, and magnesium were determined by atomic absorption. In all cases, the mean values are close to the known concentration of the solution analyzed. There are no significant differences between the percent relative standard deviations of results. The automated system may be more precise for calcium analysis, but also may be less precise for determining iron. 


\section{REFERENCES}

(1) Bristow, Q.; Anal Chem, 46, p 2246 (1974).

(2) Kelly, M. T., Stelzner, R. W., Dale, J. M., and Ferguson, M. N.; Paper Presenced to the ORNL 17th Conference on Analytical Chemistry in Nuclear Technology: Gatlinburg, Tennessee; October 23 - 25, 1973. 


\section{Distribution}

\section{Energy Research and Development}

Administration - Oak Ridge

Hickman, $\dot{H}$. D.

Leed, R. E.

Zachry, D. S., Jr

\section{Oak Ridge Gaseous Diffusion Plant}

Carpenter, L. J.

Farrar, R. B.

Kwasnoski, T.

Levin, R. W.

Stewart, J. H., Jr

Stiet, S. S.

Wilcox, W. J., Jr

Oak Ridge National Laboratory

Laing, W. R.

Rickard, R. R.

Shults, W. D.

\author{
Morrow, R. W. (10) \\ Oliphant, G. W. \\ Phillips, L. R. \\ Smith, R. D. \\ Stoner, H. H. \\ Tewes, W. E. \\ White, J. C. \\ Whitson, W. K. \\ $Y-12$ Central Files (master copy) \\ $Y-12$ Central Files (route copy) \\ $Y-12$ Central Files $(Y-12 R C)$ \\ $Y-12$ Central Files (5)
}

Paducah Gaseous Diffusion Plant

Bewley, H. D.

\section{Oak Ridge Y-12 Plant}

Alvey, H. E.

Bernander, N. K.

Briscoe, O.W.

Burditt, R. B.

Duggan, H. G.

Foulk, D. L.

Fraser, R. J.

Futrell, T. L. (5)

Hamilton, J. H.

Hopwood, W. H.

Jackson, V. C.

Joncs, F. W.

Kahl, K. G.

Keith, A.

Kite, H. T.

Larson, G. F.

Martin, W. R./Googin, J. M.

Mason, D. L.

MeBryde, W. T.

McLendon, J. D.

Morrow, M. K.

In addition, this report is distributed in accordance with the category UC-37, Instruments, as given in the USERDA Standard Distribution Lists for Unclassified Scientific and Technical Reports, TID-4500. 